\title{
Research Activities of Advanced Propulsion Technology in JAXA
}

\author{
By Takeshi KANDA \\ Space Transportation Propulsion Research and Development Center \\ Space Transportation Mission Directorate, JAXA, Miyagi, Japan
}

(Received April 25th, 2008)

\begin{abstract}
The rocket-ramjet combined-cycle engine is studied for the next space transportation in JAXA. The engine realizes a higher effective specific impulse than that of the conventional rocket engines. Engine model combustion tests were conducted in the ejector-jet mode at a sea-level static-air condition and in the ramjet mode at a Mach 4 flight condition. Flight tests with the CAMUI hybrid rocket are planed for the ejector-jet system design technology. Aerodynamic tests and combustor tests are conducted to modify the engine design technologies. Studies on the high enthalpy flow, the light weight material and the vitiation effect on the engine performances are also conducted.
\end{abstract}

Key Words: Combined-Cycle Engine, Rocket engine, Ramjet engine

\section{Introduction}

For more economical space transportation, a new system is required. Reuse of the transportation vehicle is one of the ways for the economical transportation system. At the same time, for the next generation transportation system, high reliability and abort-ability are required for credible and safety transportation of payload, including

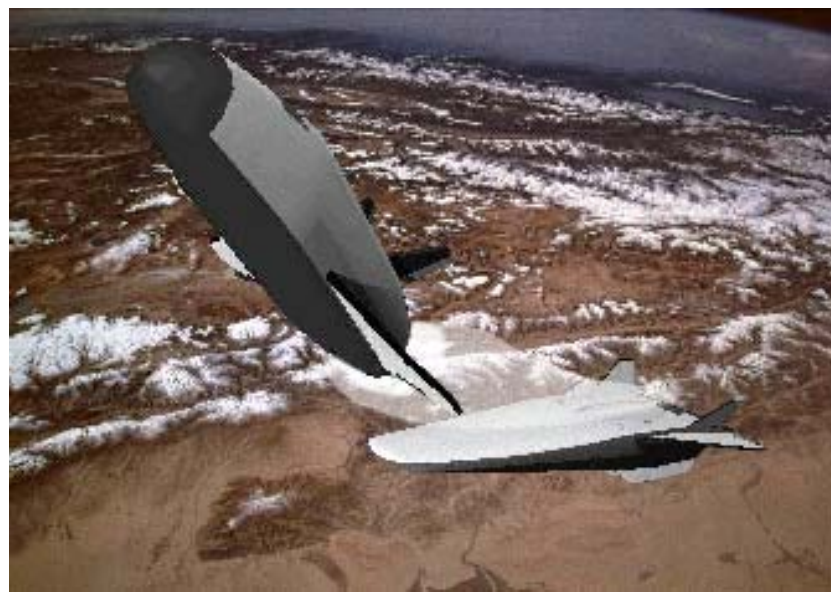

Fig. 1. An artist image of a space transportation system. tourists.

To carry out such requirements, weight margin for supplemental redundant system is necessary. Since a required velocity increment is specified by a target orbit, the specific impulse of the booster stage should be increased to realize the margin. However, present conventional liquid rocket engines produce almost an ideal specific impulse. To attain a larger specific impulse, use of an air-breathing engine has been studied in the booster stage, e.g., the turbo-ram jet engine, ${ }^{1)}$ the ram/scramjet engine. ${ }^{2)}$ Figure 1 shows an artist image of a space transportation system with the air-breathing engine in the booster stage. The kinetic energy is proportional to a square of the velocity, so the use of the air-breathing engines in supersonic or hypersonic regime is effective to attain the kinetic energy of a target orbit. The ram/scramjet engines have been studied to attain the effective acceleration of the booster stage.

Although the ram/scramjet engine has a superior specific impulse performance in the super/hypersonic region, the engine has disadvantages as a booster engine. The space transportation system needs another engine to accelerate the vehicle from take-off to supersonic speed. The system also needs another engine, e.g., a rocket engine, when the vehicle flies up to a high altitude where the atmosphere is too sparse. The transportation system

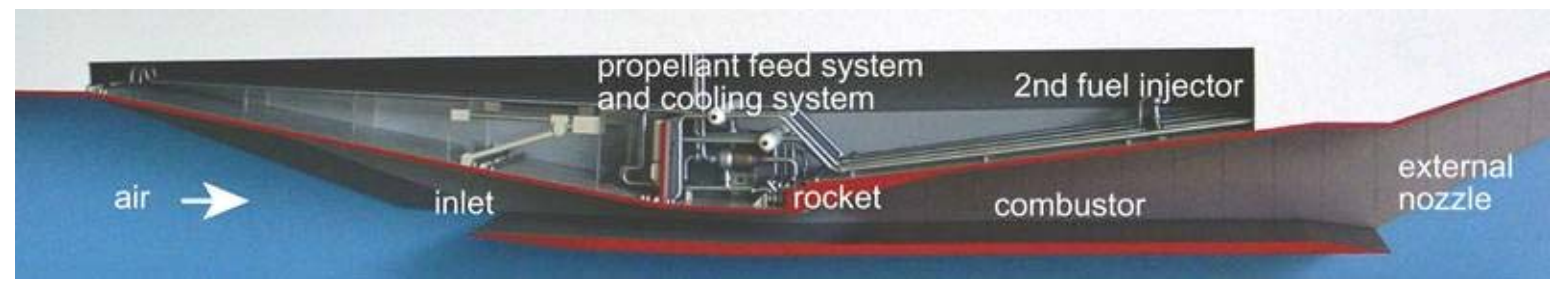

Fig. 2. Picture of a display model of rocket-ramjet combined-cycle engine. 
will become heavy due to the two or three kinds of the engines.

The rocket-ramjet combined cycle engine, i.e., the rocket based combined cycle engine (RBCC), ${ }^{3-6)}$ can operate in these different flight conditions and produce high specific impulses. Figure 2 shows a picture of a display model. Figure 3 shows engine operating modes in subsonic to transonic, supersonic, hypersonic and low-dynamic pressure flight conditions.

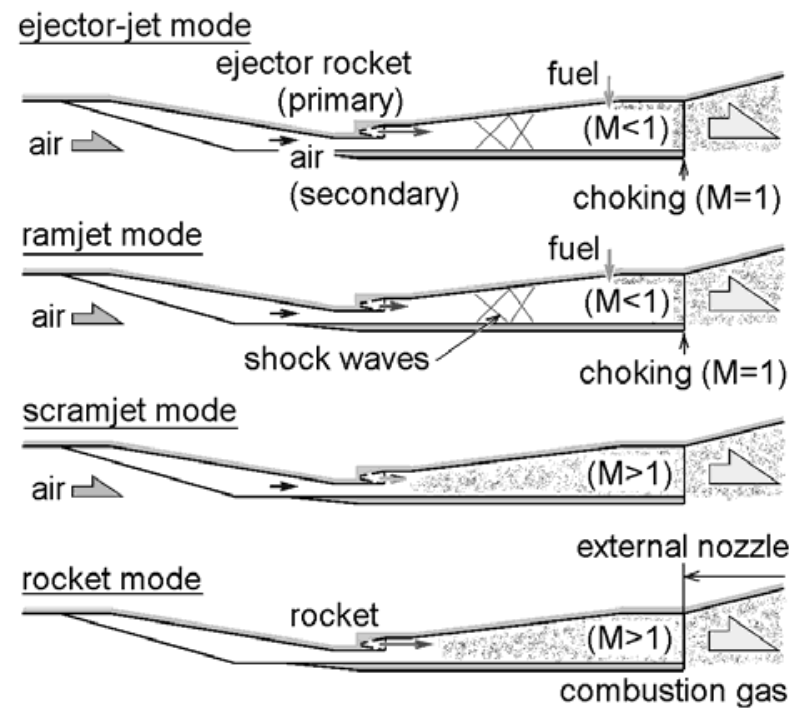

Fig. 3. Schematic diagram of operating modes of rocket-ramjet combined-cycle engine.

In the ejector-jet mode, subsonic air or unstarted air is breathed by the ejection of the rocket exhaust. Pressure of the mixture recovers in the divergent section. Combustion around the downstream of the divergent duct accelerates the mixture to sonic speed at the engine exit. In the ramjet mode, pressure of the supersonic airflow recovers in the divergent section and combustion accelerates the air to sonic speed. In the scramjet mode, secondary combustion of the hypersonic air augments thrust of the rocket engine. Even in the low-dynamic pressure condition, this combined-cycle engine operates in the rocket mode.

The inlet of this engine is still in the start condition at the staging of the Two-Stage-to-Orbit (TSTO) system. The engine can operate when the vehicle flies up to a higher altitude to inject the second stage vehicle to an ascending trajectory. Although the engine shows lower performance than those of the individual ram/scramjet engine and the rocket engine, it will be lighter and will not induce additional drag.

Japan Aerospace Exploration Agency (JAXA) has started to study the rocket-ramjet combined cycle engine. Herein, recent activities at Kakuda Space Center after the previous report ${ }^{7)}$ are presented on the scramjet engine and the rocket-ramjet combined-cycle engine.

Entry technologies are required for manned flight or re-use of space vehicles as well as those of safe, comfortable and economical access to an orbit. Study on light-weight material is also a key technology to increase the payload. At this Kakuda center, the technologies are also studied. Recent activities on these technologies are also herein presented.

\section{Scramjet Engine Studies}

The scramjet produces high specific impulse in hypersonic region theoretically. The high performance tries to be demonstrated experimentally over Mach 10 flight conditions. In the hypersonic condition, a problem is an extremely high static temperature of the combustion gas, which induces dissociation of the gas. To suppress the dissociation and establish stable combustion, three kinds of the combustor geometry of a scramjet model were examined at the High Enthalpy Shock Tunnel (HIEST). ${ }^{8)}$ Figure 4 shows a picture of the model.

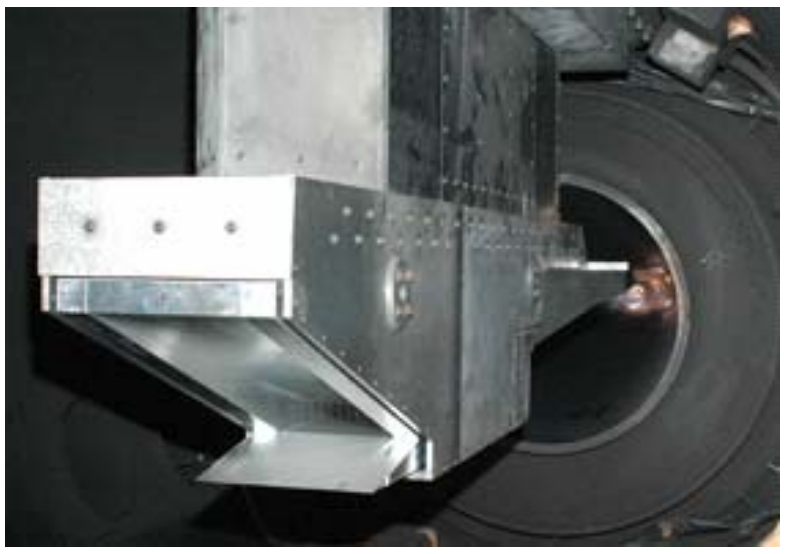

Fig. 4. A picture of the scramjet model at HIEST.

\section{Rocket-Ramjet Combined-Cycle Engine Studies}

Based on the engine components and conceptual studies, a model of the combined-cycle engine was designed and constructed to establish the engine design technologies. ${ }^{9}$ The model was tested under the ejector-jet mode at a sea-level, static-air condition (M0 condition) and was tested under the ramjet and ejector-jet modes at a Mach 4 flight condition at the Ramjet Engine Test Facility. ${ }^{10,11)}$

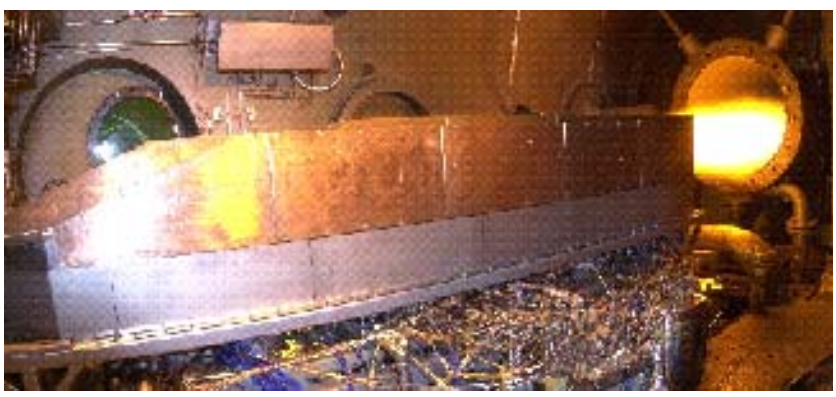

Fig. 5. Rocket-ramjet combined-cycle engine model at M0 condition in RJTF. 


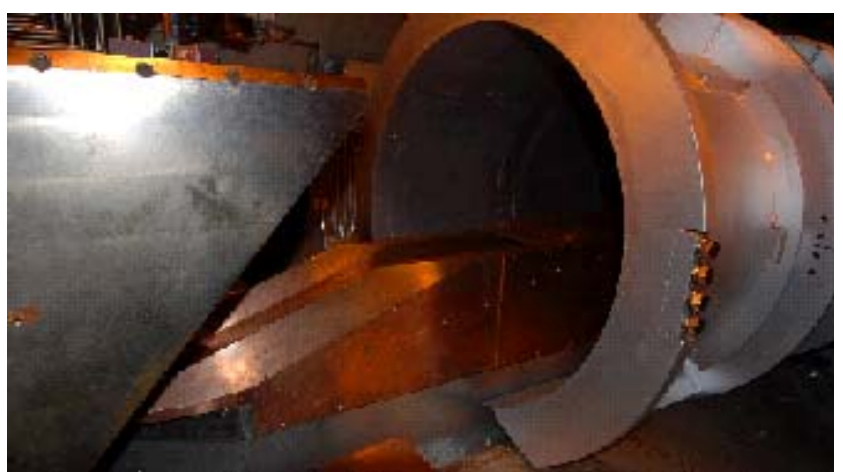

Fig. 6. Rocket-ramjet combined-cycle engine model at M4 condition in RJTF.

Figures 5 and 6 show pictures of the model at the M0 and the M4 condition tests. Operations of the ejector-jet and ramjet modes were demonstrated. Their specific impulses were not high enough for an actual use, since the model was designed for demonstration and improvement of the design technologies.

Using the same model, tests of the ramjet and scramjet modes will be conducted at Mach 6 and 8 conditions at RJTF. For combustor and engine model tests over Mach 8 condition, additional detonation facility is now under investigation for simulation of the rocket exhaust at HIEST now.

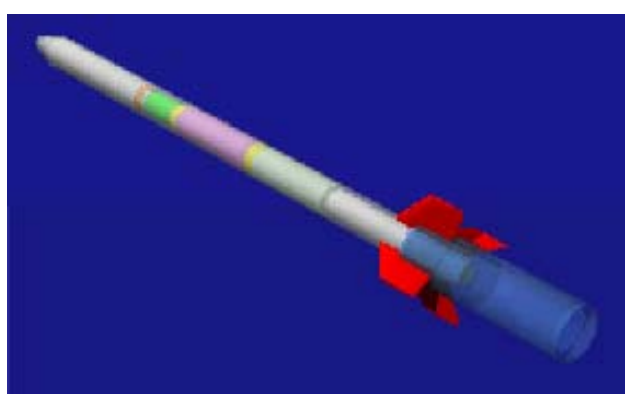

Fig. 7. CAMUI hybrid rocket with ejector duct.

The most important problem clarified from the tests is a decrease of the ejector performance due to an entropy increase due to mixing between the primary rocket exhaust and the breathed airflow. To modify the design

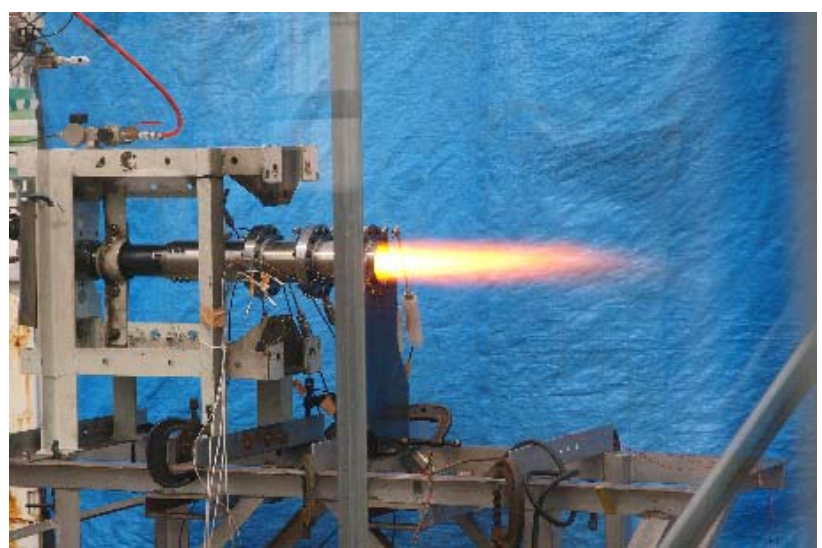

Fig. 8. Combustion test of ejector rocket CAMUI rocket.

technology of the ejector system, subsonic/transonic flight tests are planned by the CAMUI hybrid rocket ${ }^{12)}$ with Hokkaido University. In the tests, an ejector duct is attached around the CAMUI rocket nozzle. Figure 7 shows an image picture of the CAMUI rocket with the ejector duct. Prior to the flight tests, ground combustion tests were conducted in March 2008 at Uematsu Electric Co. Ltd, Akabira, Hokkaido. Figure 8 shows a picture of the test.

Other transonic characteristics of the rocket-ramjet combined-cycle engine were investigated with a small model in subsonic/supersonic wind tunnel, which was a scaled model of the engine model tested at the RJTF. ${ }^{13)}$ The rocket exhaust is substituted by nitrogen gas and the ejector performance is not exactly simulated due to its low temperature. However, the pressure distribution from the inlet to the diffuser sections can be reproduced reasonably. Acceleration to sonic speed by combustion in the engine was simulated with geometrical contraction at the model exit. Figure 9 shows a schematic of the model.

As well as the acquisition of the design technology of the ejector system, an increase of the ejector performance is also investigated to overcome the entropy increase due to the mixing. Modifications of the rocket nozzle configuration are investigated. ${ }^{14)}$

Another problem from the M4 engine model tests at RJTF was made clear. Pressure distribution in the

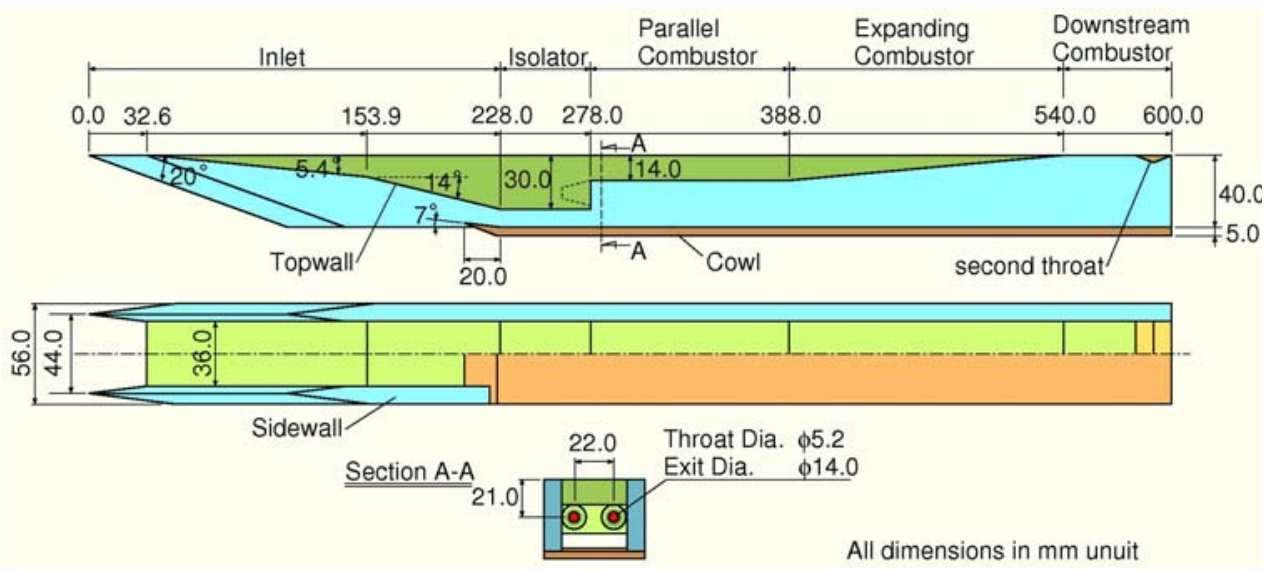

Fig. 9. Schematic scaled rocket-ramjet engine model. Rocket exhaust is simulated with N2 gas. 

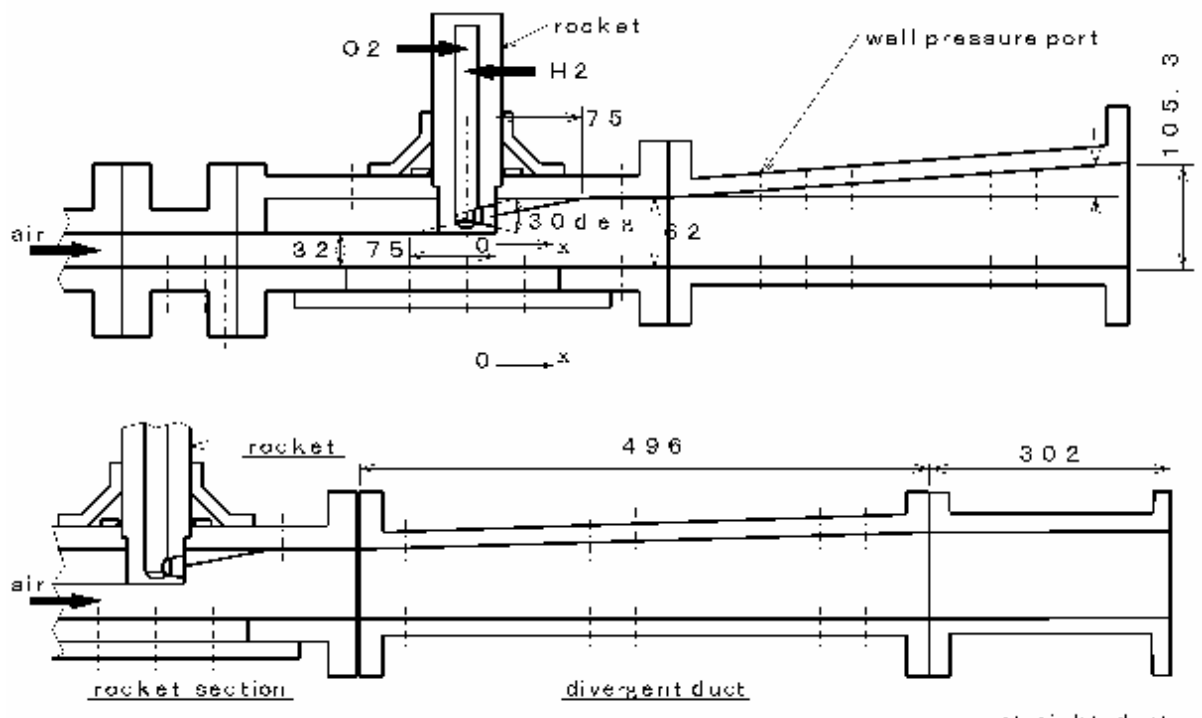

Fig. 10. Combustor model of ramjet mode tests.

divergent duct agreed with the predicted distribution approximately, but the details still showed minor discrepancies. Small difference of the wall pressure distribution in the divergent duct makes large difference of the thrust performance. Physical processes of pressure recovery, mixing and combustion are still in research subjects. In these works, ramjet mode combustor tests were conducted. Effects of the position of fuel injection and the angle of the divergent section on pressure distribution, i.e., pressure recovery, mixing and combustion processes, were investigated. ${ }^{15)}$ Figure 10 shows the experimental model.

In the scramjet mode, breathed air is at a hypersonic velocity even after the inlet compression. For augmentation of thrust due to combustion of fuel with the air, fuel injection technologies of the scramjet engine can be applied to the combined-cycle engine. For example, a arrow-shape and a diamond-shape fuel injection holes are found to be effective in penetration of fuel. ${ }^{16)}$

Throttling of the rocket engine is a key technology of the combined-cycle engine. It is now studied in the LE-X program to $60 \%$, ${ }^{17)}$ and more advancement is also studied. The combined-cycle engine can operate with other fuels. Studies with other fuel than hydrogen is conducted in the program of the regeneratively-cooled LOX/methane rocket engine now, ${ }^{18)}$ and other studies of kerosine fuel engines are also conducted.

The space transportation system is required to attain a specified velocity increment, $\Delta v$. When the air-breathing engine is adopted as a booster engine, the effective specific impulse, $I s p_{e}$, has to be used to measure the engine performance since the vehicle flies in the air with drag. ${ }^{19)}$

$$
\begin{aligned}
\Delta v & =I s p \cdot\left(1-\frac{D}{F_{\text {eng }}}\right) \ln \frac{m_{0}}{m_{1}} \\
& =I s p_{e} \cdot \ln \frac{m_{0}}{m_{1}}
\end{aligned}
$$

Isp, $D, F_{\text {eng }}, m_{0}, m_{1}$ are a specific impulse, drag, engine thrust, initial mass and final mass, respectively. The effective specific impulse of the air-breathing engine with thrust assist by the rocket engine increases with a decrease of the rocket exhaust in lower flight Mach numbers around 6. In higher Mach numbers around 10, however, the effective specific impulse increases with an increase of the rocket thrust assist. That is, thrust by only an air-breathing engine is not sufficient for acceleration to attain a specified velocity increment. The rocket-ramjet combined-cycle engine will be principally studied for the next space transportation system in the JAXA 2nd 5-year program from this 2008 .

\section{High Enthalpy Flow, Light Weight Material and Vitiation Effect on Engine Performance}

The combined-cycle engine will be used to the future space transportation system. To return to the earth safe, economically and comfortably, as well as to go to an orbit, entry technologies, i.e., high enthalpy flow technologies have to be established. Herein, their research activities are also introduced. Aero-thermodynamic characteristics in the dissociated airflow is studied at HIEST. For example, an center of pressure shifts from a position in the low-enthalpy airflow because of dissociation around the

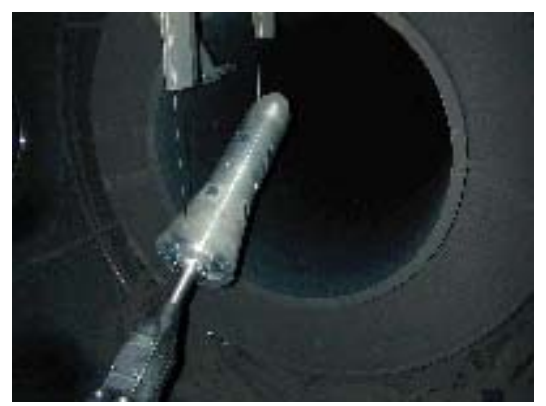

Fig. 11. HB2 model in HIEST. 
body. Figure 11 shows the HB2 model in HIEST for estimation of accuracy in force measurement of the wind tunnel.

The payload can be increased by a decrease of weight of a vehicle airframe and engines. Carbon composite material is studied to reduce the engine weight, applied to a large and low-pressure part of the engine, i.e., a rocket engine nozzle and the duct of the combined-cycle engine. Against permeability and oxidization, silicon impregnation and coatings of $\mathrm{SiC}$ and $\mathrm{SiO}_{2}$ are tried. Figure 12 shows a silicon impregnated $\mathrm{C} / \mathrm{C}$ composite test piece coated with $\mathrm{SiC}$ and $\mathrm{SiO}_{2}$. Recently, the powder jet deposition at room temperature in air is also tried. With this technology, production and maintenance become easy, and their cost are reduced.

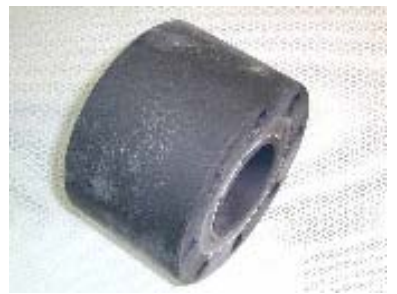

Fig. 12. C/C composite test piece impregnated with silicon and coated with $\mathrm{SiC}$ and $\mathrm{SiO}_{2}$.

These tests are conducted in the $\mathrm{H} 2-\mathrm{O} 2$ pre-combustion vitiation-heated facilities or a shock tunnel. The work gas is not the same as the air in flight, and the engine and aero-thermodynamic performances may not agree with those in actual flight. The effect of the contamination on the air should be made clear by, i.e., flight tests or tests at a ballistic range facility. Recently, the vitiation effect on the scramjet performance was made clear. ${ }^{20)}$

\section{Closing Remarks}

The Space Transportation Mission Directorate, JAXA has planned the research activities of the space transportation in the 2nd 5-year program. In the plan, the liquid rocket engine, the rocket-ramjet combined-cycle engine and other technologies are studied for the next-generation space transportation system at the Space Transportation Propulsion Research and Development Center, JAXA.

\section{References}

1) Heiser, W. H., Pratt, D. T., Daley, D. H., and Mehta, U. B.: Hypersonic Airbreathing Propulsion, AIAA Education Series, AIAA, Washington, DC, 1994, pp. 457-464.

2) Heiser, W. H., Pratt, D. T., Daley, D. H., and Mehta, U. B.: Hypersonic Airbreathing Propulsion, AIAA Education Series, AIAA, Washington, DC, 1994, pp. 22-26.

3) Escher, W. J. D., Hyde, E. H., and Anderson, D. M.: A User's Primer for Comparative Assessments of All-Rocket and
Rocket-Based Combined-Cycle Propulsion Systems for Advanced Earth-to-Orbit Space Transport Applications, AIAA Paper 95-2474, Jul. 1995.

4) Olds, J. R., and Bradford, J. E.: SCCREAM: A Conceptual Rocket-Based Combined-Cycle Engine Performance Analysis Tool, J. Propulsion and Power, 17 (2001), pp. 333-339.

5) Siebenhaar, A.: Strutjet Evolves to Meet Air-Breathing Propulsion Challenges for the 21st Century, 13th International Symposium on Air-Breathing Engines, Paper 97-7135, 1997.

6) Kanda, T., and Kudo, K.: Conceptual Study of a Combined-Cycle Engine for an Aerospace Plane, J. Propulsion and Power, 19 (2003), pp. 859-867.

7) Kanda, T.: Progress of Scramjet and Combined-Cycle Engine Research at JAXA, Proceedings of 25th ISTS, 2006-a-54, Kanazawa, Japan, Jun. 2006.

8) Takahashi, M., Komuro, T., Sato, K., Kodera, M., Tanno, H., and Itoh, K.: Improvement of Scramjet Combustor Performance with Combustor Shape at Hypervelocity Condition over Mach 10 Flight, 26th ISTS Paper 2008-a-38, Hamamatsu, Japan, Jun. 2008.

9) Kanda, T., Tomioka, S., Ueda, S., Tani, K., and Wakamatsu, Y.: Design of Sub-Scale Rocket-Ramjet Combined-Cycle Engine Model, 56th IAC Paper IAC-05-C4.5.03, Fukuoka, Japan, Oct. 2005.

10) Tomioka, S., Takegoshi, M., Kudo, K., Kato, K., Hasegawa, S., and Kobayashi, K.: Performance of a Rocket-Ramjet Combined-Cycle Engine Model in Ejector Mode Operation, AIAA Paper 2008-2618, Apr. 2008.

11) Tani, K., Izumikawa, M., Saito, T., Ono, F., and Murakami, A.: Ram and Ejector-Jet Mode Experiments of the Combined Cycle Engine in Mach 4 Flight Conditions, AIAA Paper 2008-0103, Jan. 2008.

12) Nagata, H., Ito, M., Maeda, T., Watanabe, M., Uematsu, T., Totani, T., Kudo, I.: Development of CAMUI Hybrid Rocket to Create a Market for Small Rocket Experiments, Acta Astronautica, 59 (2006), pp. 253-258, 2006.

13) Tani, K., Kouchi, T., Kato, K., Sakuranaka, N. and Watanabe, S.: Aerodynamic Experiments of Small Scale Combined Cycle Engine in Various Mach Numbers, 26th ISTS Paper 2008-a-41, Hamamatsu, Japan, Jun. 2008.

14) Hasegawa, S. and Tani, K.: Numerical Investigation of the Configuration Effects to the Ejector-jet Performance in the RBCC Engine Combustor Model, 59th IAC Paper IAC-08-C4.5.10, Glasgow, Scotland, Sep. 2008.

15) Kato, K., Kudo, K., Murakami, A., Tani, K., Kanda, T.: Ramjet-Mode Operation in a Combined-Cycle Engine Combustor, 26th ISTS Paper 2008-a-40, Hamamatsu, Japan, Jun. 2008.

16) Tomioka, S., Izumikawa, M., Kouchi, T., Masuya, G., Hirano, K., and Matsuo A. : Matched Pressure Injections into a Supersonic Crossflow through Diamond-Shaped Orifices, $J$. Propulsion and Power, 24 (2008), pp. 471-478.

17) Kanda, T., Tani, K., and Kudo, K.: Conceptual Study of a Rocket-Ramjet Combined-Cycle Engine for an Aerospace Plane, J. Propulsion and Power, 23 (2007), pp. 301-309.

18) Kurosu, A., Ogawara, A., Yamanishi, N., Onga, T., Kumakawa, A., Nishimoto, M., Manako, H., and Okita, K.: LE-X, Japan's Next Generation Booster Engine, 26th ISTS Paper 2008-a-02, Hamamatsu, Japan, Jun. 2008.

19) Azuma, N., Okita, K., Aoki, K., Kawashima, H., Yamanishi, N, Negishi, H., Manako, H., Kaneko, T. : Conceptual Study for LOX/Methan Engines :, 26th ISTS Paper 2008-a-06, Hamamatsu, Japan, Jun. 2008.

20) Tomioka, S., Hiraiwa, T., Kishida, T., and Yamasaki, H.: Evaluation of Vitiation Effects in Scramjet Engines, 26th ISTS Paper 2008-a-39, Hamamatsu, Japan, Jun. 2008. 